\title{
Hemophagocytic Lymphohistiocytosis in a Patient With Acute Respiratory Distress Syndrome Secondary to SARS-CoV-2 Infection
}

\author{
Graziana Francesca Greco ${ }^{a}$, Fabio Spreafico ${ }^{a}$, Domenica Di Costanzo ${ }^{\mathrm{a}}$, Antonietta Pecoriello ${ }^{\mathrm{a}}$, \\ Martina Garuti ${ }^{a}$, Francesco Inglese ${ }^{a}$, Giulia Cervi ${ }^{\mathrm{a}}$, Giuseppe De donno ${ }^{\mathrm{a}}$, \\ Massimiliano Beccaria ${ }^{a, b}$
}

\begin{abstract}
Hemophagocytic lymphohistiocytosis (HLH) is a potentially lifethreatening entity resulting from the dysregulated activation of Tlymphocytes. Secondary HLH (sHLH) complicates various medical conditions. Similar to 2009 H1N1 influenza, severe acute respiratory syndrome coronavirus 2 (SARS-CoV-2) infection appears to trigger a cytokine storm in a subset of individuals. The patient of 64 years old presented himself in the emergency department with cough and fever, and was subjected to the nasopharyngeal swab and tested positive for SARS-CoV-2, as expected from epidemiological data. Hospitalized in cohort isolation, he initially presented a multi-organ impairment and specifically a worsening of his renal function, initial coagulopathy, lymphopenia modest thrombocytopenia and systemic inflammatory commitment. During the course of the 6th day, a picture of a probable cytokine storm and clear multiple organ failure (MOF) was evident. Therefore a clinical diagnosis was made according to HScore criteria of secondary hemophagocytic lymphohistiocytosis. We started high-dose steroid therapy (dexamethasone $8 \mathrm{mg}$ bid). And after $36 \mathrm{~h}$, the patient was significantly improved: alert, oriented, weaned from non-invasive ventilation (NIV) and stable blood chemistry. In conclusion, in coronavirus disease 2019 (COVID-19) positive patients with evidence of cytokine storm and acute respiratory distress syndrome (ARDS), the levels of blood triglycerides and ferritin are useful and often decisive to comfort the diagnosis of sHLH if cytopenia of one or more lines is revealed.
\end{abstract}

Keywords: Hemophagocytic lymphohistiocytosis; SARS-CoV-2; ARDS

Manuscript submitted May 31, 2020, accepted July 10, 2020

Published online August 28, 2020

aSC Pneumologia e UTIR, ASST Mantova, Carlo Poma, Via Lago Paiolo 10, 46100 Mantova, Italy

bCorresponding Author: Massimiliano Beccaria, SC Pneumologia e UTIR, ASST Mantova, Carlo Poma, Via Lago Paiolo 10, 46100 Mantova, Italy. Email: massimiliano.beccaria@asst-mantova.it

doi: https://doi.org/10.14740/jmc3515

\section{Introduction}

Hemophagocytic lymphohistiocytosis (HLH) is a potentially life-threatening entity resulting from a dysregulated activation of T-lymphocytes, leading to multi-organ dysfunction, as well as proliferation and activation of benign macrophages with hemophagocytosis throughout the reticuloendothelial system and up-regulation of inflammatory cytokines [1].

Secondary HLH (sHLH) complicates various medical conditions. Infection-associated sHLH, predominantly triggered by viruses like Epstein-Barr virus or cytomegalovirus, is most frequently observed [2]. Similar to 2009 H1N1 influenza, severe acute respiratory syndrome coronavirus 2 (SARSCoV-2) appears to trigger a cytokine storm in a subset of individuals [3].

\section{Case Report}

The patient, a 64-year-old Caucasian man, non-smoker, suffered from type 2 diabetes mellitus, chronic renal failure stage IV (Kidney Disease Outcomes Quality Initiative (K-DOQI)) and hypertensive heart disease. The patient presented himself in the emergency departement with cough and fever, and was subjected to the nasopharyngeal swab and tested positive for SARS-CoV-2, as expected from epidemiological data.

Hospitalized in cohort isolation, he initially presented a $\mathrm{PaO}_{2} / \mathrm{FiO}_{2}(\mathrm{P} / \mathrm{F})$ of 300; multi-organ impairment (hematic) and specifically a worsening of his renal function with 3.91 $\mathrm{mg} / \mathrm{dL}$ of creatinine, initial coagulopathy (prothrombin timeinternational normalized ratio (PT-INR) 1.49, at partial thromboplastin time (PTT) 1.39 ratio), lymphopenia $(150 / \mu \mathrm{L})$ modest thrombocytopenia $(118.000 / \mu \mathrm{L})$ and systemic phlogistic commitment (FBG $751 \mathrm{mg} / \mathrm{dL}$; C-reactive protein (CRP) 276 $\mathrm{mg} / \mathrm{L}$, lactate dehydrogenase (LDH) $782 \mathrm{UI} / \mathrm{L}$; D-dimer 4,322 $\mathrm{ng} / \mathrm{mL}$; ferritin $1,727 \mathrm{ng} / \mathrm{mL}$ ), and triglycerides (TGs) level in normal range $(1.5 \mathrm{mmol} / \mathrm{L})$.

During the course of the 6th day, a picture of a probable cytokine storm and clear syndrome of multiorgan failure was evident with worsening of kidney damage (creatinine nadir $5.54 \mathrm{mg} / \mathrm{dL}$; LDH 1,261 UI/L; CRP $307 \mathrm{mg} / \mathrm{L}$; D-dimer 
$7,654 \mathrm{ng} / \mathrm{mL}$; and ferritin $>6,000 \mathrm{ng} / \mathrm{mL}$ ), appearance of clear dyspnea and evidence of clinical acute respiratory distress syndrome (ARDS) and radiological, acute confused state and relief of severe anemia with hemoglobin values up to $6.8 \mathrm{~g} /$ $\mathrm{dL}$ with normal reticulocytes, no evidence of acute blood loss, no significance of the auto-immune hemolysis tests and no peripheral blood smear detection. The patient needed two bags of transfusion of concentrated red blood cells. The following day, the patient also presented the appearance of significant hypertriglyceridemia (TG: $3.52 \mathrm{mmol} / \mathrm{L}$ ). At that time, the patient was taking all the usual recommended antiviral therapy.

Hypertriglyceridemia ( $>1.67 \mathrm{mmol} / \mathrm{L})$ is identified in $69 \%$ of adults with HLH and has been associated with lipoprotein lipase inhibition caused by excess tumor necrosis factor (TNF) [4]. Therefore a clinical diagnosis was made according to HS score criteria of sHLH.

\section{Discussion}

Actually, there is no perfect set of diagnostic criteria available for diagnosis of HLH, particularly in the setting of coronavirus disease 2019 (COVID-19), but currently available CSS criteria (e.g., HScore or HLH-04) can certainly guide clinicians toward the clinical diagnosis [5].

The same day, he was immediately started with highdose steroid therapy (dexamethasone $8 \mathrm{mg}$ bid). This drug was preferred because it is elective over methylprednisolone in cases where there is a suspicion of central nervous system involvement, as it is able to cross the blood-brain barrier [6]. After $36 \mathrm{~h}$, the patient was significantly improved: alert, oriented; weaned from non-invasive ventilation and stable blood chemistry (hemoglobin $10.9 \mathrm{~g} / \mathrm{dL}$, creatinine $3.52 \mathrm{mg} / \mathrm{dL}$, and CRP $61 \mathrm{mg} / \mathrm{L}$ ), which allowed transfer to the low-intensity care unit. After 1 week, the patient breathed spontaneously and was discharged home in a generally good clinical condition.

\section{Conclusions}

In conclusion, in COVID-19 positive patients with evidence of cytokine storm, the levels of blood TGs and ferritin are useful and often decisive to comfort the diagnosis of sHLH if cytopenia of one or more lines is revealed [7].

HScore can be a key in severe cases for identify a subset of selected patients in whom the use of immunosuppressant drugs can be decisive and also improve mortality.

In fact, we face a double edge sword when considering treatment with immunosuppressive drugs in those patients. On the one hand it may be useful to control the inflammatory response that certainly may be harmful for the patient; and on the other side, it could favor the virus shedding [8].

In particular, the World Health Organization (WHO) [9] and Centers for Disease Control and Prevention (CDC) [10] recommend that corticosteroids not to be routinely used in patients with COVID-19 for treatment of viral pneumonia or ARDS unless indicated for another reason.
But, for treating the severe forms of COVID-19, especially if other therapies have failed, immunosuppression could be potential treatment as a lifesaver. In this context, therapeutic options would include steroids, intravenous immunoglobulin, selective cytokine blockade (e.g., anakinra or tocilizumab) and JAK inhibition [11].

\section{Acknowledgments}

None to declare.

\section{Financial Disclosure}

No funding was received. None of the authors have disclosures relevant to this manuscript.

\section{Conflict of Interest}

None to declare.

\section{Informed Consent}

The manuscript has been sufficiently de-identified to protect the patient. He has provide informed consent.

\section{Author Contributions}

All authors contributed to the editing of the manuscript.

\section{Data Availability}

The authors declare that data supporting the findings of this study are available within the article.

\section{References}

1. Ramos-Casals M, Brito-Zeron P, Lopez-Guillermo A, Khamashta MA, Bosch X. Adult haemophagocytic syndrome. Lancet. 2014;383(9927):1503-1516.

2. Maakaroun NR, Moanna A, Jacob JT, Albrecht H. Viral infections associated with haemophagocytic syndrome. Rev Med Virol. 2010;20(2):93-105.

3. Mehmet Soy, Gokhan Keser, Pamir Atagunduz, Fehmi Tabak, Isik Atagunduz, Servet Kayhan. Cytokine storm in COVID-19: pathogenesis and overview of anti-inflammatory agents used in treatment. Clin Rheumatol. 2020;30:1-10.

4. Henter JI, Carlson LA, Soder O, Nilsson-Ehle P, Elinder G. Lipoprotein alterations and plasma lipoprotein lipase reduction in familial hemophagocytic lymphohistiocytosis. Acta Paediatr Scand. 1991;80(6-7):675-681. 
5. Fardet L, Galicier L, Lambotte O, Marzac C, Aumont C, Chahwan D, Coppo P, et al. Development and validation of the HScore, a score for the diagnosis of reactive hemophagocytic syndrome. Arthritis Rheumatol. 2014;66(9):2613-2620.

6. Henter JI, Horne A, Arico M, Egeler RM, Filipovich AH, Imashuku S, Ladisch S, et al. HLH-2004: Diagnostic and therapeutic guidelines for hemophagocytic lymphohistiocytosis. Pediatr Blood Cancer. 2007;48(2):124-131.

7. Zoller EE, Lykens JE, Terrell CE, Aliberti J, Filipovich AH, Henson PM, Jordan MB. Hemophagocytosis causes a consumptive anemia of inflammation. J Exp Med. 2011;208(6):1203-1214.

8. Alijotas-Reig J, Esteve-Valverde E, Belizna C, SelvaO'Callaghan A, Pardos-Gea J, Quintana A, Mekinian A, et al. Immunomodulatory therapy for the management of severe COVID-19. Beyond the anti-viral therapy: A comprehensive review. Autoimmun Rev. 2020;19(7):102569.

9. World Health Organization. Clinical management of severe acute respiratory infection [SARI] when COVID-19 disease is suspected Interim guidance. Pediatr Med Rodz. 2020;16(1):9-26.

10. Interim clinical guidance for management of patients with confirmed coronavirus disease [COVID-19]. https:// www.cdc.gov/coronavirus/2019-ncov/hcp/clinicalguidance-management-patients.html. 2020 COVID-19: consider cytokine storm syndromes and immunosuppression.

11. Soy M, Keser G, Atagunduz P, Kayhan S. COVID-19: consider cytokine storm syndromes. Clin Rheumatol. 2020:1-10. 